\title{
On oral calcifications: sialoliths, dental calculi and tonsilloliths
}

\author{
A.J. Anjos*, P. Nolasco**, J.M. Aquino Marques*, F. Cabrita***, M.F.C. Pereira****, A.P. Alves de \\ Matos***** and P.A. Carvalho** \\ *Faculdade de Medicina Dentária, Universidade de Lisboa, Cidade Universitária, 1649-003 Lisboa, Portugal \\ **ICEMS, Instituto Superior Técnico, Universidade de Lisboa, Av. Rovisco Pais, 1049-001 Lisboa, Portugal \\ ***Serviço de Cirurgia Maxilo-Facial, Centro Hospitalar de Lisboa Central, R. José António Serrano 1150-199 \\ Lisboa, Portugal \\ ****CEGPIST, Departamento de Engenharia Civil, Arquitectura e Georrecursos, Instituto Superior Técnico, \\ Universidade de Lisboa, Av. Rovisco Pais, 1049-001 Lisboa, Portugal \\ *****Anatomia Patológica, Centro Hospitalar de Lisboa Central - HCC, Rua da Beneficência 8, 1069-166 \\ Lisboa; Centro de Estudos do Ambiente e do Mar (CESAM/FCUL) - Faculdade de Ciências da Universidade de \\ Lisboa and Centro de Investigação Interdisciplinar Egas Moniz (CiiEM), Quinta da Granja , Monte de Caparica, \\ 2829-511 Caparica, Portugal
}

The oral cavity is susceptible to several calcifications such as salivary calculi (sialoliths), dental calculus (tartar) and tonsillar concretions (tonsilloliths). Although several individual studies had been already carried out, a comprehensive morphological and elemental comparison between them is still missing.

Sialoliths are most commonly found in the submandibular glands [1] and are composed of regions rich in $\mathrm{Ca}$ and $\mathrm{P}$ minerals, namely hydroxyapatite, whitlockite and brushite [1], and regions consisting of organic matter with highsulphur content [1]. These regions are organized in alternating concentric layers [1]. Several bacterial species have also been identified in sialoliths microstructure showing that infection occurs recurrently throughout the stone formation [2].

Generally, tartar presents an inorganic structure rich in $\mathrm{Ca}$ and $\mathrm{P}$ minerals, such as brushite, octacalcium phosphate, hydroxyapatite and whitlockite, and an organic matrix, mainly constituted by aerobic bacteria and yeast or just anaerobic bacteria [3].

Tonsilloliths occur most commonly on the crypts of the palatal tonsils and are composed of a mixture of organic matter, namely bacterial cells and epithelial debris, as well as inorganic material rich in $\mathrm{Ca}$ and $\mathrm{P}$ minerals such as hydroxyapatite. Volatile sulphur compounds produced by anaerobic bacteria are usually associated to these, in general, innocuous structures [4].

The current study involved the ultrastructure and chemical characterization of the calcified structures by scanning electron microscopy (SEM) combined with energy dispersive spectroscopy carried out with a JEOL JSM $7001 \mathrm{~F}$ instrument with an INCA pentaFetx3 Oxford spectrometer operated at $15 \mathrm{kV}$. Higher resolution characterization has been performed by transmission electron microscopy (TEM) using a H8100 Hitachi instrument operated at $200 \mathrm{kV}$. SEM samples were prepared following metallographic procedures [1], whereas TEM samples were obtained following standard biological sample preparation procedures [5].

The results show that sialoliths present the most complex structure, with a central core surrounded by concentric layers, while tartar and tonsilloliths do not have a distinctive architecture (Figures 1 (a), 2 (a) and 3 (a). At higher magnifications, layered structures, as well as crystals could be found in sialoliths and tartar (Figures 1 (b) and 2 (b). Bacteria were common in all the calcified structures, although in tonsilloliths their abundance is higher (Figure 3 (b)). All calcifications have similar elemental constitution, with $\mathrm{Ca}$ and $\mathrm{P}$, indicating the presence of calcium phosphates (Figures 1 (c), 2 (c) and 3 (c). Sulphur was also found associated with the organic matter in sialoliths and tonsilloliths, though the amounts found in the latter were much smaller than initially expected.

Based on the similarities found, new correlations between these calcification will be available. For instance, the mineralization process described in tartar can help understand the similar processes occurring in sialoliths and tonsilloliths, while the association between bacteria and sulphur in tonsilloliths can be a clue for their presence in 
sialoliths.

References

1. Alves de Matos A.P. et al., Microsc. and Microanal., 13:390, 2007.

2. Teymoortash A. et al., Acta Oto-Laryngol. 122:210, 2002.

3. Charlier P. et al., Legal Med., 12:163, 2002.

4. Tsuneishi M. et al., Microbes Infect., 8:2348, 2006.

5. Pease D.C. Histological techniques for electron microscopy, $2^{\text {nd }}$ ed. New York, USA: New York, Academic Press Inc: 1965.

The work was carried out with financial support of the Portuguese Foundation for Science and Technology through PTDC/SAU-ENB/111941/2009 and PEst-OE/CTM-UI0084/2011 grants.
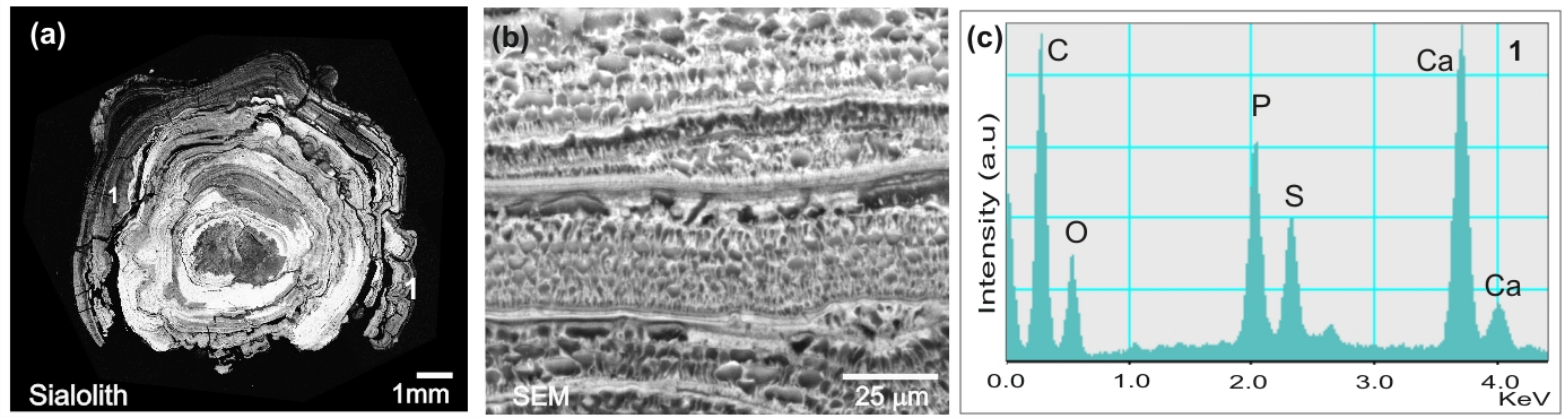

Figure 1. Morphologic characterization and elementary constitution of sialoliths. (a) General morphology, (b) alternating organic and mineralized layers and (c) EDS spectrum obtained at 1
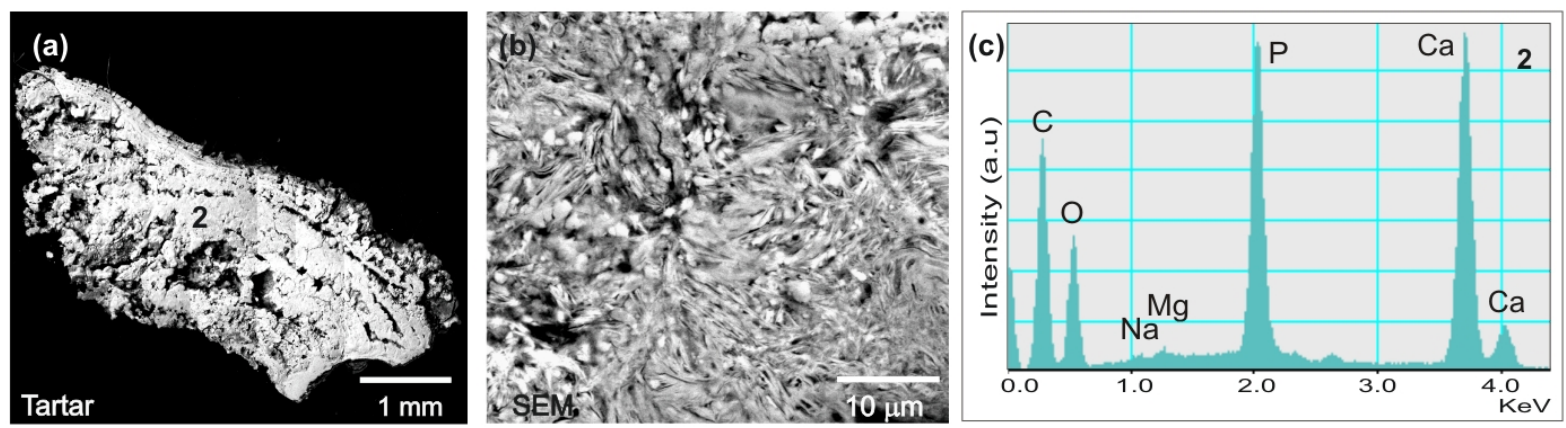

Figure 2. Morphologic characterization and elementary constitution of tartar. (a) General morphology, (b) crystals and (c) EDS spectrum obtained at 2
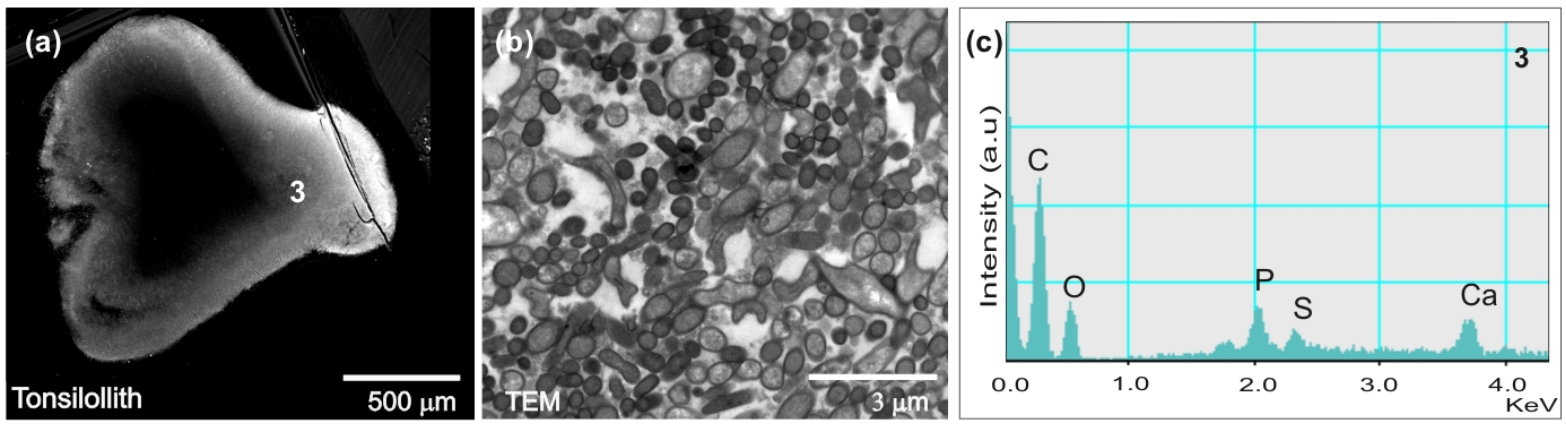

Figure 3. Morphologic characterization and elementary constitution of tonsilloliths. (a) General morphology, (b) bacteria and (c) EDS spectrum obtained at 3. 